\title{
KELSEN E O POSITIVISMO JURÍDICO CONTEMPORÂNEO: NOTAS DE UM (POSSÍVEL) ACERTO DE CONTAS
}

KELSEN AND CONTEMPORARY LEGAL POSITIVISM: NOTES FROM A (POSSIBLE) SETTLING OF THE SCORE

\section{LENIO LUIZ STRECK ${ }^{1}$}

Resumo: O Positivismo Jurídico é um paradigma complexo. Compreendê-lo em suas diversas versões e, sobretudo, por intermédio dos standards de racionalidade que o sustenta ao longo de sua história é um dos desafios da teoria do Direito de perfil hermenêutico. Neste ensaio crítico busca-se confrontar o Juspositivismo contemporâneo a partir de um dos principais teóricos desta mesma corrente de pensamento: Hans Kelsen. O texto se inicia com duas breves seções. Uma acerca da genealogia do Positivismo e a outra sobre o modo como Kelsen conseguiu desenvolver uma Ciência do Direito. Após, a discussão se volta para as seguintes falhas do positivismo jurídico hodierno: 1) a ausência de uma metalinguagem; 2) a ausência de uma preocupação com a diferença entre causalidade e imputação; 3) o paradoxo ou autocontradição exclusivista.

Palavras-chave: Hans Kelsen; Positivismo furídico; metalinguagem.

AвSTRACT: Legal Positivism is a complex paradigm. Understanding it in its various versions and, above all, through the standards of rationality that sustains it throughout its history is one of the challenges of the law theory of hermeneutic profile. In this critical essay, we try to confront contemporary Juspostivism from one of the main theorists of this same chain of thought: Hans Kelsen. The text begins with two brief sections. One about the genealogy of

1 Doutor em Direito (UFSG); Pós-Doutor em Direito (FDUL). Professor Titular da Universidade do Vale do Rio dos Sinos -UNISINOS (RS) e Universidade Estácio de Sá- UNESA (RJ). Professor Visitante da Universidade Javeriana de Bogotá, Coimbra e Lisboa (PT). Coordenador do DASEIN -Núcleo de Estudos Hermenêuticos. Procurador de Justiça (RS) aposentado. Advogado. E-mail: <lenio@unisinos.br>. 
Positivism and the other about how Kelsen managed to develop a Science of Law. Afterward, the discussion turns to the following faults of current legal positivism: 1) the absence of a metalanguage; 2) the absence of a concern about the difference between causality and imputation; 3) the paradox or self-contradiction of the exclusive positivism.

Keywords: Hans Kelsen; Legal Positivism; metalanguage.

SUMÁRIO: I. Introdução; II. Uma breve genealogia do positivismo jurídico; III. De como Kelsen separou a Ciência do Direito da moral; IV. Das falhas do positivismo contemporâneo: de quando a metalinguagem opera no mesmo nível da linguagem objeto; V. Das falhas do positivismo contemporâneo: a ausência de preocupação com a questão "causalidade versus imputação"; VI. Das falhas do positivismo contemporâneo: O paradoxo (ou a contradição) exclusivista; VII. Considerações finais; VIII. Referências.

\section{I NTRODUÇÃo}

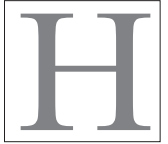

ans Kelsen está no panteão dos grandes teóricos do Direito de todos os tempos. A partir dos influxos do Neopositivsimo Lógico e do Neokantismo o jurista conseguiu elaborar uma teoria sofisticada e que enfrentava as principais questões epistemológicas da época. Assim, a Teoria Pura do Direito tornou-se um símbolo do pensamento juspositivista.

O Positivismo Jurídico pós-Kelsen foi tomando outros rumos, sobretudo, após a obra "O Conceito de Direito" de Herbert Hart, tendo como pressupostos alguns aspectos que Kelsen teve que discutir de modo explícito. Por conta disso, podemos observar alguns gaps e/ou falhas nas versões juspositivistas contemporâneas que podem ser confrontadas, paradoxalmente, por um dos corifeus desta mesma corrente de pensamento: Hans Kelsen.

Neste ensaio busca-se expor esta realidade, como um possível acerto de contas. Assim, três pontos são abordados: 1) a ausência de uma metalinguagem; 2) a não diferenciação ou a indiferença entre causalidade e imputação; 3) e o paradoxo exclusivista, em 
que "tudo" pode ser direito. Antes destas análises, serão feitas duas breves exposições acerca da genealogia do positivismo, que de um modo de controlar a prática jurídica, de dizer como o direito deve-ser, tornou-se uma postura voltada para a teoria a ciência ao mundo analítico do ser; e outro sobre o modo como Kelsen cindiu a Ciência do Direito da Moralidade e com isso conseguiu desenvolver seu projeto científico.

A partir da Crítica Hermenêutica do Direito, tentamos compreender o Positivismo Jurídico com a profundidade filosófica dos seus paradigmas subjacentes. Nesta investigação este exercício também é feito no sentido de desvelar os limites desta abordagem em confronto com alguns dos insights básicos da construção kelseneana. Pensar em qualquer possibilidade de superação paradigmática no Direito exige o esforço compreensivo de conhecer aquilo a que se está a transpor. Neste sentido se apresenta esta leitura, uma crítica desde dentro, com Kelsen contra o Positivismo Jurídico Contemporâneo.

\section{Uma breve genealogia do Positivismo Jurídico}

O Positivismo Jurídico é um fenômeno complexo. Partindo desta constatação, a Crítica Hermenêutica do Direito tem procurado compreendê-lo por intermédio de uma leitura de Filosofia do/no Direito, no intuito de não apenas descrever suas características, mas, também, desvelar os paradigmas filosóficos entendidos na linguagem de Ernildo Stein como standards/vetores de racionalidade que lhe dão sustentação.

O Juspositivismo clássico, embora cada uma das vertentes contenha diversas peculiaridades, apresenta alguns traços comuns em todas elas. Trata-se de um movimento em que o material jurídico é estabelecido por alguma autoridade humana legitimada: na França, a lei produzida pelo legislador racional, de inspiração iluminista (Escola da Exegese); na Alemanha, os conceitos gerais e abstratos deduzidos pelos juristas-professores (Jurisprudência dos Conceitos); 
na Inglaterra, os precedentes proferidos pela autoridade política competente (Jurisprudência Analítica). No dizer de R. C. Van Caenegem $^{2}$ este cenário apresentava o direito dos juízes, legisladores e professores. Veja-se que é isto que o positivismo posteriormente chamaria de (tese dos) "fatos sociais" (source thesis), embora nesse momento histórico não seja da simples caracterização como "fato social" que derive a validade do Direito, mas da sua relação concreta com a autoridade criadora. Dito de outro modo, o Juspositivismo foi se consolidando com afastamento de qualquer justificação metafísica do direito. Legisladores, professores e juízes simbolizam a suficiência do humano para criar e/ou dizer o direito válido, sem qualquer necessidade de um elemento transcendente, ou de uma adequação à alguma ordem supratemporal.

Este impulso emancipador que está no embrião do Positivismo Jurídico, também esteve presente no Positivismo Científico, para o qual só há fatos. E aqui a conexão com os paradigmas filosóficos fica absolutamente clara. Trata-se de reflexos do paradigma da filosofia da consciência, em que a razão humana põe o sentido das coisas. Ou, no plano da discussão aqui posta, a razão "põe o Direito". Daí a raiz do Positivismo Jurídico: Direito é um fato social posto pela razão humana e que cinde direito e moral, o que possibilitou mais à frente a ilusão teórica de que poderia descrever, de modo neutro, o direito cindido.

Não esqueçamos que o conceito de "positivismo jurídico" tem como ponto central a tese de que o Direito é um fato social posto pela mão humana. Eis a raiz do empirismo que sustenta os positivismos científicos e jurídico. Como em Comte e Durkheim, fatos sociais são como coisas. ${ }^{3}$ Ora, coisas são verificáveis; são descritíveis.

2 Ver Caenegem, R. C., van. Juizes, legisladores e professores, Rio de Janeiro: Elsevier, 2010.

${ }^{3}$ Cf. Comte, Auguste, Curso de filosofia positiva, Madrid: Magisterio Español, 1987; Durkheim, Emile, As Regras do Método Sociológico, São Paulo: Martin Claret, 2001. 
Eis a tarefa do cientista; eis a tarefa do jurista positivista: descrever fatos, ou seja, descrever o Direito.

O positivismo científico de Auguste Comte, é bem verdade, ganhou força a partir da década de 1840; tanto é que os primeiros positivistas jurídicos, anteriores ao positivismo comteano, como vimos, não se denominavam positivistas: tratavam suas teorias a partir da expressão genérica jurisprudência -entendida aqui não como um conjunto de decisões reiteradas dos tribunais, mas como teoria do Direito.

Não por menos, a origem do termo positivismo, no Direito, é, no mínimo, controversa. O próprio Ronald Dworkin, em seu Modelo de Regras $I,{ }^{4}$ ao enfrentar o positivismo de Austin e, especialmente, Hart, após expor tais teorias, diz que passará a chama-las, "com alguma imprecisão histórica", de "positivismo jurídico". Não é por outra razão, obviamente, que alguns autores como Norberto Bobbio sustentam que a expressão positivismo jurídico sequer teria relação com o positivismo científico, mas, sim, com a locução direito positivo. ${ }^{5}$

É evidente que a origem do termo é controversa; inegável também que o Positivismo Jurídico veio antes do apogeu do Positivismo Científico. Contudo, o fato de os positivistas jurídicos terem sido assim chamados somente anos depois - Hart é, provavelmente, um dos primeiros positivistas a se definir como tal ${ }^{-6}$ é justamente um indicio de que há uma relação com o paradigma filosófico a partir do qual trabalha o positivismo científico. Antes dele, Hans Kelsen afirmou expressamente

4 Dworkin, Ronald, Levando os direitos a sério, Tradução de Nelson Boeira, São Paulo: Martins Fontes, 2012, p. 27.

5 Bobbio, Norberto, O positivismo jurídico: lições de filosofia do Direito. Tradução e notas de Márcio Pugliesi e Edson Bini, São Paulo: Ícone, 1999, p. 15. Não é possível concordar com essa afirmação de Bobbio. Não há possibilidade ou viabilidade epistêmica falar em positivismo jurídico sem o relacionar com o positivismo científico.

6 Hart, H. L. A., O conceito de direito, Tradução de Antônio de Oliveira Sette Câmara, Revisão da tradução: Marcelo Brandão Cipolla, São Paulo: Editora WMF Martins Fontes, 2012. 
que sua teoria pura do direito era positivista. ${ }^{7}$ Mais do que isso, negar essa inexorável ligação, ou este tronco comum, é insistir em um Direito como ciência, como técnica; é separar Direito e filosofia, como se tudo fosse, mesmo, uma questão de dogmática. É como se não fosse possível falar sobre paradigmas filosóficos. Como se discricionariedade, decisionismos e voluntarismos fosse uma "coisa natural", "que nada tem a ver com o paradigma da filosofia da consciência", ${ }^{8}$ ou com o "sujeito moderno".

Lembro também que o Juspositivismo primevo (Escola da Exegese, Jurisprudência dos conceitos e Jurisprudência analítica) tinha como preocupação central encontrar um método seguro que desse conta da prática jurídica. Já as versões a partir de Kelsen redirecionaram o foco de análise para a teoria, a ciência do direito, passando a apresentar a seguinte característica comum: a pretensão de metodologicamente assumir um caráter descritivo de cunho adequacionista. As proposições descritivas produzidas pelo positivismo, em sua pretensão de negar qualquer tipo de metafísica, no sentido ontoteológico, ${ }^{9}$ tratam a verdade como uma adequação do intelecto ao objeto: com Smilg Vidal, ${ }^{\circ}$ podemos dizer que, nesse paradigma, o mundo é compreendido como um conjunto de substâncias que possuem determinadas propriedades. A função do intelecto huma-

7 La teoría pura del derecho es positivismo jurídico, es simplemente la teoría del positivismo jurídico; y el positivismo jurídico está íntimamente vinculado con el relativismo. Kelsen, Hans.¿Qué es la Teoría Pura del derecho?, 5ª ed., Colonia del Carmen-MEX: Distribuciones Fontamara, 1997, p.31.

8 Trindade, André Karam y Streck, Lenio Luiz, "Diário de Classe: Alexy e os problemas de uma teoria jurídica sem filosofia”, Revista Consultor furídico, São Paulo, 05 abr. 2014. Disponível em: <https://www.conjur.com.br/2014-abr-05/ diario-classe-alexy-problemas-teoria-juridica-filosofia >. Acesso em: 17 out. 2017.

9 Para maiores aprofundamentos ver SteIn, Ernildo, Às voltas com a metafisica $e$ a fenomenologia, Ijuí, RS: Unijuí, 2014.

10 Vidal Smilg, Norberto, Possibilidades y limites de la compreensión de la verdade como "adecuación", in: Nícolas, Juan António; Grodin, Jean (Orgs.), Verdad, hermenenéutica, adecuación, Madri: Tecnos, 2016, p.47-48. 
no consistiria, basicamente, em captar essa realidade e expressa-la usando a linguagem como uma ferramenta. Aliás, não é por menos que o maior analítico da atualidade, Ernst Tughendat, assume a verdade como adequação.

Esta postura metodológica inicial teve como referência as ciências naturais e exatas, lócus onde o método científico primeiro floresceu. Tal empreendimento ficou conhecido como Fisicalismo. ${ }^{11}$ Assim, a realidade tornou-se apenas aquela fração passível de observação e experimentação empíricas, a partir de uma racionalidade matematizante. Sobre aquilo que não se enquadrasse neste recorte epistêmico, nada haveria a ser dito na condição de um cientista (do direito).

Nesse sentido, é paradigmático o capítulo oitavo da Teoria Pura do Direito. Hans Kelsen é explícito ao afirmar a limitação do teórico quanto à interpretação/aplicação do direito. Ele pode apenas descrever possíveis significações dentro de uma moldura normativa, pois faz um ato de conhecimento a partir do material jurídico disponível. Todavia, ele não pode prescrever, dizer qual é a interpretação correta, pois isto é um ato de vontade realizado pelo juiz, e por isso não poderia ser seguramente antecipado por uma ciência que descreve aquilo que é, mas não o que deve ser. Ou seja, o dualismo metodológico entre ser e dever ser (sein-sollen), impôs um descritivismo supostamente neutro.

Ainda que as versões juspositivistas posteriores a Kelsen, como aquela desenvolvida por H.L.A Hart, tenham se afastado de uma perspectiva fiscalista, é inegável que a postura apenas descritiva da teoria se manteve como uma das principais características desta

11 A respeito da relação da perpectiva fisicalista e a teoria kelseneana Cláudio Michelon Jr. Aforma que: de um lado, tanto realistas quanto Kelsen ligam a objetividade (o que pode ser descrito) a um "mundo físico", a um "mundo do tempo e do espaço" etc. e, dessa forma, pretendem privilegiar a ciência que se tornou o padrão para o conhecimento "absoluto" (independentemente de nossa perspectiva): a física. Michelon JR, Cláudio Fortunato. Aceitação e objetividade: uma comparação entre as teses de Hart e do positivismo precedente sobre a linguagem e o conhecimento do direito. São Paulo: R. dos Tribunais, 2004, pp.116-117. 
corrente, mesmo havendo, ainda que minoritariamente, propostas normativas.

\section{iil. De como Kelsen separou a Ciência do Direito da} MORAL

Como já abordado, esta busca por uma teoria neutra e atemporal já é vista em Kelsen. Entretanto, o jurista entendia que esta objetividade, possível no campo científico, não o seria na aplicação do Direito, estando o juiz desvinculado da lei, dos conceitos e dos precedentes. Assim, pensava porque entendia que o ato de aplicação, a ser feito pelo sujeito moderno, inexoravelmente estaria comprometido por influências externas, como a moral e a política. Contudo, o material jurídico - a norma- criada pela autoridade competente poderia ser analisado pelo cientista/teórico do Direito, que o descreveria sem fazer qualquer juízo de valor. Por isso a sua interpretação -que é a do cientista do Direito- é um ato de conhecimento. Com esta cisão epistêmica Kelsen procura colocar-se fora do discurso e do contexto sobre o qual analisa e, com isso, não recair no paradoxo do mentiroso/do cretense/de Epiménedes. ${ }^{12}$

Duas tradições de pensamento contribuíram para esta abordagem kelseniana. De um lado o Neopositivismo Lógico do Círculo de Viena ${ }^{13}$ e do outro o Neokantismo. A primeira tinha como um

12 Epiménedes disse: “Todos os cretenses são mentirosos". Sendo ele um cretense poderia sua afirmação ser verdadeira? Em síntese, uma das maneiras de resolver este paradoxo seria colocando-se num lócus epistêmico diverso daquele sobre o qual se enuncia. Kelsen tentou fazer isso a partir de um ponto de vista fisicalista, ou seja, a partir de lugar nenhum. Já Hart e seus seguidores, tiveram mais problemas, pois assumiram uma posição de observador externo, mas ainda no mesmo nível do objeto de análise.

13 Nesse contexto, é importante destacar que, embora Kelsen tenha dito que não pertenceu e não teve influência do Círculo de Viena, trata-se de um esclarecimento que fez em um dado contexto e em uma carta (trata-se de uma resposta da Hank Mulder, em maio de 1963). No entanto, nessa mesma carta, 
dos propósitos centrais construir uma linguagem científica rigorosa, afastada das ambiguidades e dos conceitos metafísicos presentes na linguagem ordinária. Buscava-se desenvolver uma linguagem lógica ou de segundo nível (metalinguagem) que não fosse refém da subjetividade da linguagem natural (linguagem objeto). Como resultado, seria possível fazer Ciência, ter um conhecimento seguro. A segunda, dentre as suas várias preocupações, compreendia que a ciência constrói seu próprio objeto de conhecimento, que logicamente, pressuporia um princípio unificador. É a razão que ordena o caos da realidade. Deste modo, a partir deste arcabouço Kelsen encontrou um modo de descrever \ordenar cientificamente o fenômeno jurídico. Ressalte-se que ambas correntes partilhavam do dualismo metodológico, sendo a dimensão do ser, dos fatos, aquela sobre a qual recairia o labor científico.

Deste modo, caso o cientista do direito dissesse qual é a melhor interpretação de uma determinada norma, estaria proferindo um juízo de valor que, enquanto herdeiro dessas tradições, acreditava se tratar de um enunciado desprovido de rigor científico. Seriam apenas opiniões políticas, ideológicas, morais, crenças religiosas, etc. No entanto, na prática judiciária, o juiz precisa aplicar uma norma

Kelsen reconhece que os escritos de Philipp Frank e Hans Reichenbach sobre a causalidade influenciaram, sim, sua visão. $\mathrm{O}$ teor da carta é encontrado em texto de Clemens Jabloner, que afirma que, embora as ideias de Kelsen não estivessem livres da metafísica, o jurista de Viena seguiu uma tendência que se pode encaixar na corrente neopositivista lógica. Cf. Jabloner, Clemens, "Kelsen and his Circle: The Viennese Years", European fournal of International Law, n. 9, 1998, pp. 378-380. Além do mais, há que se ter em mente o seguinte: jamais disse que Kelsen é um neopositivista lógico por essência. Digo -com Warat, com Leonel Severo Rocha, até mesmo com Norberto Bobbio e Luigi Ferrajoli -que há uma influência, e ela é muito clara. Não somos os únicos. Vladimir de Carvalho Luz, Manoel da Nave Pires, Juan Cofré, todos sustentam essa influência em obras bastante rigorosas que merecem destaque. Cf. Luz, Vladimir de Carvalho, "Neopositivismo e Teoria Pura do Direito", Revista Sequência, n. 47, 2003, pp. 11-31. Cofré, Jua, "Kelsen, el formalismo y el Círculo de Viena", Revista de Derecho de la Universidad de Valdivia, vol. 06, dez. 1995, pp. 29-37. 
ao caso concreto. Não pode apenas descrever o Direito. Por isso, a prescrição decorrente do ato de aplicação do Direito (sentença) será um ato de vontade, pois ele escolhe qual a interpretação da norma que lhe convier, segundo sua subjetividade, que está imersa num contexto de influências difusas. Por isso, aliás, contemporaneamente, o jurista italiano Pierluigi Chiassoni afirma que a interpretação por parte dos órgãos de aplicação possa ser, como na visão escandalosa (para Alice) de Humpty-Dumpty, um jogo interpretativo de reinterpretação ilimitada. ${ }^{14}$

Nesse aspecto, fica evidente a influência que Kelsen sofre quando busca edificar a ciência do Direito em um segundo nível, libertando-a de todos os elementos que, nas suas próprias palavras, lhe são "estranhos": a psicologia, a sociologia, a ética e a teoria política. Com isso, o objeto da ciência jurídica passa a ser o Direito, que é, assim, a linguagem-objeto, descrito por uma metalinguagem, a Ciência Jurídica (esse é o lugar da teoria pura). O caráter dualístico também está presente na TPD seja na norma hipotética fundamental (Grundnorm), nas relações dela derivadas às demais normas, como também na veraficabilidade das descrições normativas, já que "podem ser aplicados às proposições jurídicas que descrevem estas normas e que, por sua vez, podem ser verdadeiras ou falsas". ${ }^{15}$

Deste modo Kelsen conseguiu descrever o Direito. Todavia, para isso teve que apelar para a artificialidade; para uma metalinguagem. O olhar é puro; o olhado não o é. Por isso, Teoria do Pura do Direito e não Teoria do Direito Puro.

14 Chinssoni, Pierluigi, O enfoque analítico na filosofia do direito: de Bentham a Kelsen, São Paulo: Editora Contra Corrente 2017, p.489.

15 Kelsen, Hans, Teoria Pura do Direito, trad. João Baptista Machado. São Paulo, Martin Fontes, 1985, p. 82. 
IV. DAS FALHAS DO POSITIVISMO CONTEMPORÂNEO: DE QUANDO A MEtAlinguagem OPERA NO MEsmo Nível DA Linguagem OBJETO

O positivismo jurídico contemporâneo parece que não compreendeu a complexidade da Teoria Pura do Direito. Aliás, alguns não entenderem sequer o título da obra: é a teoria pura do Direito e não a teoria do Direito puro, na medida em que Kelsen percebe que a linguagem natural (eivada de subjetivismos) não daria conta de um projeto descritivo neutro. O jurista criou, assim, a metalinguagem de uma linguagem objeto. Isto é, colocou sua teoria noutro patamar epistêmico. Em livro recentemente traduzido (2017), Chiassoni afirma que

as doutrinas do conhecimento que proporcionam os ingredientes para as diferentes (sub)epistemologias kelsenianas são basicamente três: o construcionismo, que representa a divisa metodológica associada à obra de Rudolf von Jhering, Georg Jellinek e a doutrina do direito público alemã de finais o século XX; o construcionismo, próprio da epistemologia transcendental de Kant e dos neokantianos; o empirismo, próprio dos teóricos das ciências naturais (Ernst Mach) e sociais (Max Weber) no começo do século XX e, também, do positivismo lógico. ${ }^{16}$

Veja-se: quando um positivista pretende descrever o Direito de forma neutra ele esquece que não está fora do Direito fazendo isso, apesar de tentar colocar-se na posição do observador externo. Ainda que tente, de modo artificial, colocar-se num âmbito teórico devidamente esterilizado, tal pretensão é impossível, já que parte do Direito que está impregnado de moral. Assim, na contramão de muitos juspostivistas, tenho afirmado que é a moralidade que separa Direito e Moral. Ou seja, quem separou Direito e Moral foi

16 Chinssoni, Pierluigi, O enfoque analítico na filosofia do direito: de bentham a kelsen, São Paulo: Editora Contra Corrente, 2017, p. 419-420. 
a Moral. O erro das metalinguagens que o Positivismo Jurídico tem produzido sobre o direito é que ainda estão pressupondo um ponto arquimediano, sobre uma prática interpretativa (Dworkin). Há uma reflexão de Michael Löwy sobre positivismo científico que se aplica perfeitamente ao positivismo jurídico, mormente os positivismos pós-hartianos com pretensão descritiva:

A "boa vontade" positivista enaltecida por Durkheim e seus discípulos é uma ilusão ou uma mistificação. Liberar-se por um esforço de objetividade das pressuposições éticas, sociais ou políticas fundamentais de seu próprio pensamento é uma façanha que faz pensar irresistivelmente na célebre história do Barão de Münchhausen, ou este herói picaresco que consegue, através de um golpe genial, escapar ao pântano onde ele e seu cavalo estavam sendo tragados, ao puxar a si próprio pelos cabelos... Os que pretendem ser sinceramente seres objetivos são simplesmente aqueles nos quais as pressuposições estão mais profundamente enraizadas. ${ }^{17}$

Aliás, a descrição neutra pretendida por muitos teóricos possivelmente advém de uma metodologia que procura não recair na "falácia naturalista". ${ }^{18}$ Deste modo, assume a postura que existiria uma espécie de barreira entre o ser e o dever-ser; ou seja, de uma premissa do tipo "ser" não se seguiria, necessariamente, uma premissa do tipo "dever-ser". Dessa forma, acreditam que trabalham com uma postura arquimediana que não incorre em nenhuma espécie de valoração. O equívoco, aqui, é o esquecimento de que, ao assumir que você deve separar o Direito da moral, você já está partindo de uma posição moral. É moralmente defensável que a

17 Cf. Löwy, Michael, As Aventuras de Karl Marx contra o Barão de Münschausen: marxismo e positivismo na Sociologia do Conhecimento, São Paulo: Editora Busca Vida, 1998, p. 31.

18 A falácia naturalista é atribuída ao filósofo inglês George Edward Moore que sem seu livro Principia Ethica, um dos clássicos da filosofia do séc. XX, identificou o equívoco das teorias naturalistas que consideravam, em suma, o dever ser como propriedades "naturais" do ser, ou seja confundiam o dever-ser com o ser. 
teoria proceda desta maneira, ao invés de engajar-se com a prática, ou seja, avaliá-la

Existem muitos autores que trabalham esse colapso entre a dicotomia ser/dever-ser, fato/valor, na filosofia. Maclntyre demonstra, em After Virtue, que o bom e o ruim de forma alguma são independentes do conceito empregado. Em dois exemplos distintos, demonstra que das premissas aparentemente descritivas de que "o relógio não marca corretamente a hora" e o "fazendeiro teve um índice de produção maior do que todos os outros" se seguem, logicamente, as premissas avaliativas "o relógio é ruim" e o "fazendeiro é bom". MacIntyre acertadamente argumenta que "o conceito de relógio não pode ser definido independentemente do conceito de um bom relógio e o conceito de fazendeiro independentemente do bom fazendeiro". ${ }^{19}$

Isso significa que os positivistas não conseguem descrever o Direito apartado do conceito do "bom Direito". Assim ao descreverem o Direito estão também o prescrevendo, ainda que parcialmente, isto é, dentro dos limites daquilo que pretendem descrever.

Neste sentido, Joseph Raz, um dos expoentes do positivismo exclusivo, ${ }^{20}$ ao dizer o que apenas as fontes sociais reivindicam autoridade está, logicamente, assumindo uma prescrição contrária à Dworkin, por exemplo. Está, em outros termos, dizendo que a verdade moral (objetiva) não deve ser levada em consideração como Direito. Ainda que se argumente que isto se dá devido a pretensão de autoridade que o Direito possui, de modo ter primazia no confronto com outras razões para agir, isto também se justificaria moralmente no conceito de serviço que legitima esta reivindicação.

19 Macintyre, Alasdair, After Virtue: A Study in Moral Theory, 3. ed., 2007, p. 57-58.

20 Para maiores aprofundamentos ver verbete Positivismo furídico em Streck, Lenio Luiz, Dicionário de Hermenêtica: quarenta temas fundamentais de Teoria do Direito à luz da Crítica Hermenêutica do Direito, Belo Horizonte: Letramento/Casa do Direito, 2017, pp. 159-210. 
Dito de outra forma, é moralmente defensável que o direito se imponha na esfera pública, senão teríamos a todo tempo uma abertura ampla para razões de natureza diversa o que seria um problema para a estabilidade social. Portanto, não há somente descrição, pois descreve-se prescrevendo e prescreve-se descrevendo.

Os próprios positivistas reconhecem isso, ficando evidente com os seguintes exemplos:

1. Scott Shapiro, em Legality, ${ }^{21}$ admite que, em pelo menos alguns casos, não há como ser somente descritivo, necessitando de um engajamento normativo;

2. Jules Coleman afirma que a tese da separabilidade entre Direito e Moral é incompatível com o positivismo exclusivo, na medida em que um positivista exclusivo já parte de um ponto de vista moral (de que é bom separar o Direito da Moral) para descrever de forma neutra o que é Direito excluindo a moral; ${ }^{22}$

3. Raz afirma que "...creio que Hart se equivoca neste ponto, e Dworkin é correto ao sustentar que a explicação da natureza do direito implica considerações avaliativas" ${ }^{23}$ e, por fim;

4. a própria ideia de ponto de vista interno de Hart implica o abandono de uma descrição neutra. Diz Hart, sobre o ponto de vista externo, que "o seu ponto de vista será semelhante ao daquele que, depois de ter observado durante algum tempo o funcionamento de um sinal de trânsito numa rua de grande movimento, se limita a dizer que,

21 Vide especificamente a nota de rodapé n. 2 do primeiro capítulo. SHAPIRO, Scott, Legality, Cambridge: Harvard University Press, 201 1, p. 403.

22 COLEMAN, Jules. La arquitectura de la filosofía del derecho. Neutralidad y teoría del derecho Madrid: Marcial Pons, 2012, p. 142 e ss.

23 RAz, Joseph, "Two views of the nature of the theory of law: A partial comparison", Legal Theory, Volume 4, pp. 5-6; 267-268. 
quando as luzes passam a encarnado, há uma probabilidade elevada de que o trânsito pare. Ele trata a luz apenas como um sinal natural de que as pessoas se comportarão de certos modos, tal como as nuvens são um sinal de que virá chuva" ${ }^{24}$. Assumir uma posição, externa ou interna, implica limites morais para a realização de qualquer empreendimento teórico.

5. Se o positivismo apostasse, efetivamente, em um "processo descritivo" de âmbito filosófico, deveriam seus teóricos demonstrar que é possível realizar esse tipo de descrição objetiva dos fatos (Direito é um fato social); ou isso ou será impossível separar Direito e Moral. A menos que o positivismo jurídico possa ser teorizado à revelia dos paradigmas filosóficos.

Parece evidente que prescrição e descrição não estão separados por uma barreira intransponível que nos permitiria transitar de modo seguro num dos lados sem a contaminação do outro. Kelsen, antes de todos, conseguiu ver que se atuasse no nível da linguagem ordinária -dimensão em que o Juspositivismo tem operado desde Hart- estaria sujeito a esta realidade e que somente noutro nível estaria a salvo, ao menos, logicamente. Assim, amparado no neopositivismo lógico e no neokantismo, a Teoria Pura do Direito não descreve nem de dentro, nem de fora, mas a partir de lugar nenhum. Obviamente, que esta pretensão é também problemática, mas demonstra uma tentativa sofisticada de não recair na aporia ainda presente no positivismo hodierno.

24 HaRt, Herbert, O Conceito de Direito, Lisboa: Fundação Calouste Gulbenkian, 2011 , p. 99. 
V. Das falhas do positivismo CONTEMPORÂNEO: A AUSÊNCIA DE PREOCUPAÇÃo COM A QUESTÃo "CAUSALIDAdE VERSUS IMPUTAÇÃO"

Outra questão que passa despercebida pelos positivismos contemporâneos, provavelmente por se supor superada, é a diferenciação entre causalidade e imputação. Hans Kelsen, tendo como um dos problemas centrais em seu horizonte de preocupações a cientificidade do direito, teve que enfrentar e apresentar uma saída para esta questão tormentosa.

Para Kelsen, a norma é um sentido objetivo imputado a um ato (de vontade). Dessa forma, Kelsen consegue delimitar com uma precisão o objeto da ciência do Direito. Prima facie, como o critério kelseniano para identificar o Direito é a norma tudo o que for, por assim dizer, normativo, interessa ao cientista do Direito. Porém, não é qualquer norma, mas somente aquelas emanadas pelas fontes socialmente autorizadas. O crucial é que este dever-ser ao ser manifesto torna-se um dado da realidade, um ser, não por uma relação de causa-efeito, mas por uma imputação.

É a imputação que afasta o Direito das ciências naturais e consequentemente de seus métodos de abordagem, e o coloca no campo das ciências culturais, normativas, ou do "espírito". É a imputação, enquanto manifestação da vontade, que ordena o caos do real, possibilitando, portanto, descrições factíveis, observáveis, que podem compor um quadro lógico rigoroso.

Antes da imputação no direito nós temos apenas a expectativa, a potência, múltiplas possibilidades sobre as quais qualquer pretensão científica estaria fadada ao fracasso, pois inexistiria capacidade de antecipação diante do imprevisível. Se este recorte epistêmico, que possibilita a elaboração de uma metalinguagem jurídica, não for observado, teríamos uma pseudociência do direito, muito próxima da política, da moral, da ideologia. 
A partir de Hart, com sua notória ênfase sociológica, esta diferenciação tornou-se presumida. Assim, os juspositivistas, pós-Hart, de um modo geral, tendem a não mais enfrentar esta discussão. Todavia, ao não fazer isto, recaem no mesmo problema de tentar fazer ciência no andar de baixo e com isso e por isso parecem confundir os domínios do direito com os da ciência do direito.

Tomemos por exemplo a ordem proferida por um salteador, a mesma ilustração que o Hart utilizou para demonstrar as limitações do modelo de Austin. O que diferencia a ordem do assaltante de uma regra jurídica? Esta resposta pode ser dada por vários ângulos, mas o que nos importa é a ideia de validade e não de imputação, que os positivistas desde Hart veem sustentando, apesar de algumas variações. A ordem do criminoso não é válida pois não está de acordo com uma prática complexa (regra de reconhecimento), por isso não é jurídica. O que distingui é um critério fático (tese das fontes sociais), mas em Kelsen esta distinção se dá pela incidência de um princípio epistemológico: a imputação. Por isso o ato do salteador é só diferente do coletor de impostos na imputação, porque de forma causal o efeito (resultado) é o mesmo. É só na imputação (dever ser) é que está a diferença. Ao usar a dimensão sócio-prática para a verificação da juridicidade e daquilo que pode conhecido como direito, os positivistas passaram e fazer teoria na e a partir da linguagem comum. Kelsen, reconhecendo a impossibilidade deste projeto, como no paradoxo do cretense, utiliza um pressuposto lógico, o que eleva a ciência para outro patamar.

Isso difere um pouco em Raz, quem trabalha com o conceito de razões, por exemplo. Contudo, também não faz a diferenciação entre metalinguagem e linguagem objeto, nem entre imputação e causalidade. No mesmo exemplo dos salteadores, parece haver alguma autoridade que reivindica obediência exclusiva aos seus preceitos, mas não no sentido de uma autoridade (legítima) como ocorre no direito. Novamente, o critério é fático. Kelsen talvez diria que o fator fundamental para a identificação do Direito não parece ser a 
autoridade que reivindica o Direito, mas antes, o sentido jurídico que se atribuí a um ato. É inegável a superioridade kelseniana nesse ponto também.

\section{DAS FALHAS Do POSITIVISMO CONTEMPORÂNEO: O PARADOXO (OU A CONTRADIÇÃO) EXCLUSIVISTA}

Joseph Raz nos diz que o direito opera como "razões excludentes". Isto é, quando do momento de tomada de decisões e apresentar uma razão jurídica esta prevalece sobre as demais pela pretensão de autoridade que possui. Estas razões de tipo jurídica provém das fontes sociais, e por isso compõe um universo finito chamado "Direito". Como observaremos, o paradoxo ou contradição exclusivista resulta da própria operacionalidade deste sistema jurídico.

Vejamos: um positivista exclusivo dirá que o Direito reivindica autoridade, mas, entretanto, o juiz, por ter responsabilidade enquanto funcionário público, em determinados casos, poderá vir a deixar de apresentar razões com respaldo de autoridade, por exemplo, nos casos difíceis em que os limites do direito precisam ser transpostos.

Neste ponto, o positivismo exclusivo pode sofrer uma forte objeção interna, porque pode ficar refém de sua própria teoria, uma vez que aquilo que o juiz utilizar como fundamento de sua decisão se transforma, no momento posterior, em norma jurídica válida. Isto porque o positivista terá que descrever esse Direito. E sem fazer juízos morais. Consequentemente, na medida em que, para o positivismo exclusivo Direito e moral são cindidos, separados, a tarefa do positivista é descrever o Direito. Mesmo as decisões proferidas à revelia do Direito - e que se transformam em Direito- sob o argumento de juízos práticos, são Direito. Em um segundo momento, já estarão incorporados no Direito. E serão objetos de uma descrição que esconde os fundamentos morais, políticos, entre outros, que serviram de base para sentença. Assim, a pretensa separação entre Direito e Moral é fragilizada. 
Em Kelsen as decisões tomadas fora da moldura também se tornam Direito, mas para ele isto não é um problema, pois se encontra em outra dimensão analítica. Ademais, como já mencionado, ele não separa o Direito da Moral.

Veja-se que isso impede, inclusive, que se admita que os assim denominados easy cases sejam respeitados. Dizer o que é um easy case já é um hard case. Afinal, Riggs. vs. Palmer não seria um easy case? Eis o ponto. Não é por outro motivo que Scott Shapiro admite que a discricionariedade judicial recai inclusive sobre eles. ${ }^{25} \mathrm{O}$ ponto é que o positivismo não lida -e nem pode- com uma teoria da decisão. Nesse sentido, Horácio Neiva, em sua dissertação de mestrado intitulada Uma Crítica Metodológica ao Positivismo de Foseph Raz, sustenta que é preciso ao dizer que somente é possível uma teoria da decisão positivista se for uma

[...] teoria que encare os deveres dos juízes, e a forma moralmente correta de tomada de decisão judicial, como sendo uma aplicação estrita de 'normas positivadas' através de alguma forma de interpretação textual (seja através do significado histórico, seja por meio do significado literal) [2016b, p. 21].

Caso contrário, restará um problema: no plano da teoria tudo é verificado e identificado, expungindo o joio do trigo. Ocorre que, na hora da aplicação, corre-se o risco de o juiz se insurgir contra esse "produto da descrição" e lançar mão de seus próprios argumentos morais, misturando, novamente, joio e trigo. Veja-se o que diz um positivista normativo brasileiro:

O positivismo jurídico, mesmo nas suas versões seguidoras da tese da fonte social -como a ora sustentada [o positivismo normativo] não nega que a argumentação do magistrado muitas vezes é permeada por uma complexa gama de princípios morais, tampouco que a atividade do magistrado, cuja função não se confunde com o

25 Shapiro, Scott, Legality, Cambridge: Harvard University Press, 2011, p. $254-256$ 
teórico incumbido de descrever o Direito, pode ser uma atividade moralmente valorativa. ${ }^{26}$

De novo estamos diante do problema do paradoxo ou autocontradição. É evidente que determinados positivistas dirão, como repto, de que eles não estão e nunca estiveram preocupados com a decisão e que esta argumentação sobre os déficits na aplicação não lhes diz respeito. Outra vez, se o repto dos positivistas for nesse sentido, nele mesmo estará a confissão da cisão entre descrição e prescrição, já tratada anteriormente. A resposta do positivismo pode ser metodologicamente correta. Porém, a teoria do Direito não se resume ao debate metodológico. Não foi por nada que Norberto Bobbio classificou o positivismo em três aspectos: metodológico, ideológico e teórico.

\section{vil. Considerações Finais}

Afora o problema da impossibilidade de um ponto arquimediano e do paradoxo, ou contradição interna, em que todos os positivismos descritivos -inclusive Kelsen- recaem, ele ainda consegue superar os demais, permanecendo noutro patamar na medida em que resolveu o "paradoxo do cretense" e soube identificar a diferença entre causalidade e imputação. Inegavelmente, Kelsen foi -e ainda é- o positivista mais sofisticado até hoje.

De novo: eis o problema do DNA do Direito. Parece que a principal teoria jurídica não conseguiu responder à pergunta: o que fazer com a moral. Muitas propostas teóricas já foram elaboradas. Mas sempre falham porque não conseguem alcançar o melhor dois dos mundos: descrever e ao mesmo tempo obrigar os juízes a aplicar o que foi descrito. Se obrigam, já não são positivistas.

26 Torrano, Bruno, Democracia e respeito à lei: entre positivismo jurídico e pós-positivism, Lúmen Juris: Rio de Janeiro, 2015, p. 71. 
Diante do estado de natureza que perpassa a aplicação do direito no Brasil, seria desejável que a tese de Raz sobre a autoridade do Direito vinculasse os juízes. Todavia, isso envolveria um juízo acerca da aplicação. E o positivismo não se preocupa com a decisão.

A isto alguém poderia objetar: "-Mas existe o positivismo normativo ou com pretensão normativa”. Todavia, até esse tipo de positivismo admite juízos morais corretivos. Então, como ele poderá ainda assim ser positivista? Talvez o positivismo não possa ser uma teoria do direito, passando ou sendo apenas uma Teoria Política. Ou se assumir como uma teoria textualista, em que texto e norma seriam a mesma coisa. Mas isso seria um retorno ao século XIX.

A partir de um olhar hermenêutico, não há qualquer problema em se admitir ou reconhecer a linguagem natural, com a qual se trabalha, possui uma efetiva dimensão valorativa. E, ao contrário de Kelsen, não existe a ilusão com a construção de uma linguagem artificial. A linguagem, que nos marca, nos determina, é nossa condição de possibilidade.

Assim, a crítica aqui feita assume uma postura efetivamente prescritiva, partindo de uma valoração de como o direito deve-ser, observando, ao mesmo tempo, como o direito é. Para isso, busca construir critérios para que a decisão judicial não seja um ato de vontade, isolado ou discricionário.

Parte-se assim de um ponto de vista moral bem claro: de que é ruim que decisões jurídicas sejam arbitrárias e discricionárias e que é bom que a autonomia do Direito seja respeitada e que a democracia seja preservada.

Em suma, para além da perspectiva analítico-descritiva, parte-se dessa valoração moral para prescrever que o Direito não deve ficar refém da moralidade particular e arbitrária de cada julgador. É possível -e necessário- ir além dos positivismos contemporâneos, mas isso não nos impede de reconhecer que estes poderiam tornar-se ainda mais robustos se dessem ouvidos a Hans Kelsen. Talvez seja necessário um acerto de contas. 


\section{REFERÊnCIAS BibliográficAS}

Bobbio, Norberto. O positivismo jurídico: lições de filosofia do Direito. Tradução e notas de Márcio Pugliesi e Edson Bini. São Paulo: Ícone, 1999

Caenegem, R. G. van. Juízes, legisladores e professores. Rio de Janeiro: Elsevier, 2010.

Chinssoni, Pierluigi. O enfoque analítico na filosofia do direito: de Bentham a Kelsen. São Paulo: Editora Contra Corrente, 2017.

Cofré, Juan. Kelsen, el formalismo y el Círculo de Viena. Revista de Derecho de la Universidad de Valdivia, vol. 06, dez. 1995, pp. 29-37.

Coleman, Jules. La arquitectura de la filosofía del derecho. Neutralidad y teoría del derecho Madrid: Marcial Pons, 2012.

Comte, Auguste. Curso de filosofía positiva. Madrid: Magisterio Español, 1987.

Durkheim, Emile. As Regras do Método Sociológico. São Paulo: Martin Claret, 2001.

Dworkin, Ronald. Levando os direitos a sério. Tradução de Nelson Boeira. São Paulo: Martins Fontes, 2012.

Hart, H. L. A. O conceito de direito. Tradução de Antônio de Oliveira Sette Câmara. Revisão da tradução: Marcelo Brandão Cipolla. 1. ed. São Paulo: Editora WMF Martins Fontes, 2012.

Michelon JR, Cláudio Fortunato. Aceitação e objetividade: uma comparação entre as teses de Hart e do positivismo precedente sobre a linguagem e o conhecimento do direito. São Paulo: R. dos Tribunais, 2004.

Jabloner, Glemens. Kelsen and his Circle: The Viennese Years. European Journal of International Law, n. 9, 1998, pp. 378-380.

Kelsen, Hans. ¿Qué es la Teoría Pura del derecho? $5^{\text {a }}$ ed. Colonia del Carmen-MEX: Distribuciones Fontamara, 1997.

Kelsen, Kelsen. Teoria Pura do Direito. Trad. João Baptista Machado. São Paulo, Martin Fontes, 1985. 
Löwy, Michael. As Aventuras de Karl Marx contra o Barão de Münschausen: marxismo e positivismo na Sociologia do Conhecimento. São Paulo: Editora Busca Vida, 1998.

Luz, Vladimir de Carvalho. Neopositivismo e Teoria Pura do Direito. Revista Sequência, n. 47, 2003, pp. 11-31.

RAz, Joseph "Two views of the nature of the theory of law: A partial comparison". Legal Theory. Volume 4.

Shapiro, Scott. Legality. Cambridge: Harvard University Press. 2011.

stein, Ernildo. Às voltas com a metafísica e a fenomenologia. Ijuí, RS: Unijuí, 2014

Streck, Lenio Luiz. Dicionário de Hermenêutica: quarenta temas fundamentais de Teoria do Direito à luz da Crítica Hermenêutica do Direito. Belo Horizonte: Letramento/Casa do Direito, 2017.

Trindade, André Karam. STRECK, Lenio Luiz. Diário de Classe: Alexy e os problemas de uma teoria jurídica sem filosofia. Revista Consultor Jurídico. São Paulo, 05 abr. 2014. Disponível em: <https://www. conjur.com.br/2014-abr-05/diario-classe-alexy-problemas-teoria-juridica-filosofia>. Acesso em: 17 out. 2017.

Torrano, Bruno. Democracia e respeito à lei: entre positivismo jurídico e pós-positivismo. Lúmen Juris: Rio de Janeiro, 2015.

Vidal Smilg, Norberto. Possibilidades y limites de la compreensión de la verdade como <<adecuación $>>$. In: NÍCOLAS, Juan António; GRODIN, Jean (Orgs.). Verdad, hermenenéutica, adecuación. Madri: Tecnos, 2016. 